\title{
EDUCAÇÃO, CIDADANIA E COMPETITIVIDADE: QUESTÕES EM TORNO DE UMA NOVA AGENDA
}

\author{
ALMERINDO JANELA AFONSO \\ Instituto de Educação e Psicologia da Universidade do Minho - Portugal. \\ ajafonso@iep.uminho.pt \\ FÁTIMA ANTUNES \\ Instituto de Educação e Psicologia da Universidade do Minho - Portugal. \\ fantunes@iep.uminho.pt
}

\section{RESUMO}

Há alguns anos tem-se firmado o debate em torno de uma agenda política e teórica que procura defender e sustentar uma articulação possível entre a procura de competitividade das economias e a manutenção e desenvolvimento dos direitos, nomeadamente sociais, que viabilizam e constituem condições de cidadania. Neste debate, que é atravessado por distintas posições, argumentos e propostas, a educação e formação são apontadas como eixos decisivos daquela articulação. A nossa argumentação vai no sentido de mobilizar análises e investigações em Ciências Sociais, trazendo para o centro da discussão questões e problemas que freqüentemente têm sido omitidos. Defendemos que, pelo contrário, é do confronto dessas questões e problemas que depende a possibilidade de constituir uma agenda política e teórica merecedora de crédito para uma via de desenvolvimento humana, social e ecologicamente sustentável.

EDUCAÇÃO - CIDADANIA - CIÊNCIAS SOCIAIS

\begin{abstract}
EDUCATION, CITIZENSHIPAND COMPETITIVENESS: QUESTIONSAROUND ANEW AGENDA. It has been growing the debate around a political and theoretical agenda that argues for the articulation between the search of competitiveness of the economies and the development of the social rights, which make possible conditions for citizenship. Although the different positions, arguments and proposals that cross this debate, education and formation have been pointed as decisive axes of that articulation. Our argumentation aims to call up Social Sciences analysis and research bringing to the centre of the discussion questions and problems, which frequently have been neglected. We stand up for that only scrutinising these questions and problems it will be possible to constitute a consistent political and theoretical agenda towards a human, social and ecologically sustainable development
\end{abstract}


Passadas quase duas décadas de hegemonia ideológica neoliberal, são hoje visíveis, nomeadamente pelos indicadores disponíveis relativos às desigualdades e à exclusão sociais, os efeitos das políticas que promoveram a precariedade do emprego e a retração ou aumento da vulnerabilidade de outros direitos sociais. As interpretações desta situação e os posicionamentos em face das conseqüências referidas são naturalmente muito divergentes. Como seria de esperar, os arautos do pensamento único não atribuem às políticas neoliberais o aumento da exclusão social mas parecem concordar que essa questão não pode deixar de ser confrontada com alguma urgência desde que isso, evidentemente, não entre em conflito com as lógicas competitivas de uma economia capitalista cada vez mais globalizada. Por outro lado, alguns dos atuais governos, nomeadamente de países que integram a União Européia e que reivindicam o lugar de renovadores da herança trabalhista, social-democrata ou socialista, adotando pressupostos próximos da chamada terceira via, têm igualmente inscrito nos seus programas, ou apregoado com alguma insistência, ser necessário compatibilizar as exigências decorrentes da competitividade econômica e os direitos sociais e de cidadania. Finalmente, alguns reconhecidos analistas, pensadores e cientistas sociais, mesmo com percursos intelectuais e políticos diferenciados, embora, quase sempre, tenham afirmado posições ideologicamente identificáveis com a esquerda, defendem a necessidade de encontrar saídas realistas que (tendo já pouco a ver com aquelas que poderão ter defendido quando acreditavam nas grandes narrativas emancipatórias) constituam, ainda assim, alternativas merecedoras de crédito que reatualizem valores a elas referenciados ou, pelo menos, que garantam a manutenção de direitos mínimos como antídoto aos ditames do pensamento único, o qual tem-se mostrado altamente eficaz para promover a aceitação das supostas inevitabilidades do neoliberalismo e de algumas tendências da globalização.

A equação competitividade e cidadania parece assim expressar a única alternativa capaz de constituir ou, pelo menos, de promover a adesão a um novo consenso social.

Trata-se, por isso, de uma equação altamente sedutora porque pode criar a ilusão de que é possível ultrapassar as razões e motivações (completamente antagônicas em muitos casos) que fariam nesse momento convergir, na defesa de um projeto comum, quer os ideólogos do neoliberalismo quer os seus críticos. O texto que a seguir se desenvolve procura precisamente enunciar, ainda que de forma bastante provisória, algumas das linhas de análise que atravessam este debate. Nele, como se verá, as problemáticas da competitividade e da cidadania são consideradas dimensões articuláveis por meio de um novo papel que, se supõe, a educação e a formação deverão necessariamente assumir. 


\section{A ECONOMIA GLOBAL E A HEGEMONIA DO CAPITALISMO NEOLIBERAL}

Tendo em conta o contexto descrito, duas precauções teóricas parecem de antemão decisivas para pensar de uma forma mais ampla a educação e as políticas educacionais neste final de século: por um lado, procurar conhecer os efeitos da transição de uma economia mundial para uma economia global e, por outro, ponderar as conseqüências sociais da atual hegemonia do capitalismo neoliberal e dos seus postulados ideológicos.

Relativamente ao primeiro aspecto, sabemos que as novas tecnologias da informação e da comunicação permitem agora superar decisivamente os limites de tempo e de espaço que estruturavam a anterior economia mundial, e que este fato foi decisivo para iniciar a transição para uma economia global que se distingue justamente pela acrescida "capacidade de funcionar como unidade em tempo real à escala planetária” (Castells, 1997, p. 120). Trata-se, portanto, de uma economia informacional e global que, na perspectiva de Manuel Castells, apresenta as seguintes características:

É informaciona/porque a produtividade e competitividade das unidades ou agentes desta economia (quer sejam empresas, regiões ou nações) dependem fundamentalmente da sua capacidade de gerar, processar e aplicar com eficácia a informação baseada no conhecimento. É globa/porque a produção, o consumo e a circulação, assim como os seus componentes (capital, mão-de-obra, matérias-primas, gestão, informação, tecnologia, mercados) estão organizados à escala global, quer de forma direta, quer mediante uma rede de vínculos entre os agentes econômicos. É informacional e global porque, nas novas condições históricas, a produtividade gerase e a competitividade exerce-se por intermédio de uma rede global de interação. (...) O vínculo histórico entre a base de conhecimento-informação da economia, o seu alcance global e a revolução tecnológica da informação é que dá origem a um sistema econômico novo e distinto. (Castells, 1997, p. 93, tradução nossa)

Apesar de as novas condições de desenvolvimento do capitalismo estarem se alterando em ritmos muito distintos, conforme, por exemplo, as especificidades dos diferentes países no contexto nacional e mundial, a educação tem sido apontada como uma contribuição decisiva, nem sempre problematizada e, por isso, aparentemente consensual, para, nos limites de uma economia globalizada, assentada no conhecimento e nas tecnologias da informação, levar os indivíduos a perceber a dimensão das mutações em curso e as suas conseqüências, nomeadamente em termos do aumento ou da diminuição das probabilidades individuais de incorpora- 
ção em novas formas de organização do trabalho, bem como em termos de indução ou bloqueio de oportunidades de emprego, e de criação de condições materiais para definir opções de vida e projetos pessoais e familiares. Sendo, todavia, útil não sobrepor conceitualmente, e não reduzir unidirecionalmente as diferentes e contraditórias conseqüências possíveis do uso e da expansão das tecnologias da informação, sabe-se que um dos seus efeitos mais prováveis refletir-se-á na maior hierarquização de algumas formas, ou mesmo de novas formas, de organização do trabalho. Como esclarece ainda Manuel Castells, a economia informacional/global conta sobretudo com aqueles trabalhadores que, mediante educação e formação, tenham incorporado as disposições e competências necessárias para redimensionar as estruturas do sistema econômico capitalista: a competitividade, decorrente da flexibilidade, e a produtividade, baseada na inovação:

Neste novo sistema de produção redefine-se e diferencia-se o papel do trabalhador (...). Uma diferença tem a ver com o que denomino trabalhador genérico diante do trabalhador autoprogramável. A qualidade crucial para diferenciar estes dois tipos de trabalhador é a educação e a capacidade de aceder a níveis superiores de educação; isto é, a incorporação de conhecimento e informação. O conceito de educação deve distinguir-se do de qualificação. Esta pode tornar-se rapidamente obsoleta pela mudança tecnológica e organizativa. A educação (...) é o processo mediante o qual as pessoas, quer dizer, os trabalhadores, adquirem a capacidade de redefinir constantemente a qualificação necessária para uma tarefa determinada e de aceder às fontes e aos métodos para adquirir a referida qualificação. Quem possui educação, no contexto organizativo adequado, pode reprogramar-se para as tarefas em mutação constante do processo produtivo. (Castells, 1998, p. 375, tradução nossa)

No âmbito da União Européia, constituída em grande medida para poder funcionar e desenvolver-se como um dos pólos mais competitivos no contexto da economia global, têm sido produzidos relatórios e estudos setoriais que apontam com insistência para o papel estratégico da educação e da formação. Refira-se, por exemplo, os Livros Brancos da Comissão Européia (Ensinar e aprender: rumo à sociedade cognitiva e Crescimento, competitividade, emprego: os desafios e as pistas para entrar no século $X X \mid$ ) que constituem os dois documentos mais freqüentemente evocados sobre a problemática em análise. No primeiro documento, ressalvando que "a educação e a formação não podem por si só resolver a questão do emprego e, de um modo mais geral, a da competitividade das indústrias e dos serviços" (Comissão Européia, 1995, p.5) atribuiu-se-lhes, no entanto, um papel central não apenas porque são consideradas as pedras angulares da sociedade cognitiva, como 
também porque se espera que contribuam para a coesão social e para a prevenção da exclusão. Do mesmo modo, o segundo documento referido afirma:

Para o relançamento do crescimento, a renovação da competitividade e o restabelecimento de um nível de emprego socialmente aceitável na Comunidade, a educação e a formação - paralelamente à sua missão fundamental de promoção do desenvolvimento individual e dos valores da cidadania - são incontestavelmente chamadas a desempenhar um papel determinante. (Comissão Européia, 1994, p. 139)

Observa-se ainda neste mesmo documento que muitas das exigências que pesam sobre os sistemas de educação e formação são percebidas como contraditórias, porque se espera que tais sistemas

...resolvam os problemas de competitividade das empresas, a crise do emprego, o drama da exclusão social e da marginalidade, em suma, que ajudem a sociedade a ultrapassar a suas atuais dificuldades e a controlar as profundas mutações que hoje em dia atravessa. (Idem, ibidem)

No entanto, apesar de aí se explicitar alguma consciência dessas solicitações contraditórias, apenas referidas de passagem, as reiterações da importância da educação e da formação para a resolução dos problemas da competitividade e, sobretudo, do emprego, sobrepõem-se a todos os outros fatores em jogo e, desse modo, aquelas diferentes solicitações não chegam a ser discutidas nas suas implicações. Assim, na enumeração dos fatores que supostamente podem contribuir para a melhor solução dos problemas criados pelas mutações econômicas em curso, as políticas do Estado e das instâncias européias e a ação dos agentes econômicos parecem menos decisivas do que a ação dos sistemas educacionais ou a própria iniciativa dos indivíduos. A estes, aliás, se dirige uma grande parte dos argumentos produzidos quando se refere, por exemplo, ao "papel central da iniciativa individual na construção da sociedade cognitiva" ou quando se diz que "o indivíduo torna-se o agente e principal construtor da sua qualificação" (Comissão Européia, 1995, p. 7 e I8). Este é, seguramente, um dos pontos mais controversos dos atuais discursos oficiais sobre as políticas de educação e formação.

Certamente que ao analisar mais de perto os contextos e os textos em que a expressão sociedade cognitiva (ou sociedade da aprendizagem) é evocada poderse-á constatar que os seus significados não são convergentes, expressando ora a necessidade de os indivíduos terem uma educação e uma formação permanentes ou ao longo da vida (lifelong education), ora a necessidade de as organizações produtivas e de serviços se tornarem elas próprias, cada vez mais, lugares qualificantes 
e promotores de aprendizagens (/earning organisations), ora, ainda, a necessidade de a própria sociedade aprender a desenvolver a sua capacidade reflexiva, num sentido próximo ao proposto por Ulrich Beck e outros autores'. Entretanto, em termos de discursos oficiais e de orientações vindas de instâncias como a União Européia, ao sobrevalorizar-se nomeadamente o pressuposto de que a aprendizagem que conta é aquela que se guia pela maximização da sua utilidade econômica imediata - utilidade esta justificada em termos de uma racionalidade idêntica à da teoria do capital humano-, a idéia da sociedade de aprendizagem é instrumental e redutora, ainda que seja possível, a partir da sua problematização, verificar que poderá cumprir outras funções latentes mais amplas ${ }^{2}$. No que diz respeito, mais concretamente, aos documentos europeus sobre educação e formação, nos quais a mesma idéia de sociedade cognitiva ou da aprendizagem está presente, algumas leituras mais críticas dos seus pressupostos têm salientado que neles subjazem nomeadamente

...preocupações de regulação e de controle social que têm por objeto a socialização dos futuros trabalhadores, de modo a favorecer: i) a estimulação, motivação e disponibilidade para o emprego; ii) a constituição e reforço de uma ética e identidade capazes de resistir a uma "vida ativa" estruturada em torno da precariedade, ou da total ausência, de vínculos ao trabalho; iii) a legitimação e a despolitização do desemprego com base nas deficiências individuais; iv) a estratificação da força de trabalho através da aquisição de distintas "qualificações". (Antunes, 1996, p. II 2 ) $^{3}$

I. A este propósito Michael Young et al. escrevem: "Implícita no conceito de uma sociedade de aprendizagem está, por exemplo, a idéia de que uma sociedade inteiramente humana é aquela em que toda a vida social envolve aprendizagem. Por outras palavras afirma-se que o que distingue uma sociedade de aprendizagem moderna de todas as sociedades anteriores é a sua capacidade para aprender ou para ser reflexiva, como Beck, Giddens e Lash ( 1994) a interpretam. $\bigcirc$ conceito de uma sociedade de aprendizagem proporciona-nos, assim, uma base para comparar as sociedades existentes em termos da sua capacidade reflexiva" (1997, p. 528).

2. Considerando que a sociedade da aprendizagem é, em grande medida, um mito e um conceito ideológico, Christina Hughes e Malcolm Tight escrevem: "Em suma, podemos concluir que a função do mito da sociedade de aprendizagem é proporcionar uma fundamentação lógica e um acondicionamento convenientes e agradáveis para as políticas atuais e futuras de diferentes grupos de poder da sociedade. Como tal, aquele (mito) tem pouco impacto na natureza, conteúdo ou implementação dessas políticas, fazendo, mesmo assim, essas políticas aparecerem diferentes e mais interessantes, dando a impressão aos leigos interessados de que as coisas estão a melhorar. Sobretudo podemos compreender a sociedade de aprendizagem como um conceito ideológico que serve objectivos ideológicos" (Hughes, Tight, 1995, p. 302).

3. Num texto recente em que analisa a vinculação da educação-formação com o emprego, Lucie Tanguy chama a atenção para os aspectos ideológicos presentes, quando se procuram estabelecer "relações lineares e necessárias" que escondem "ao mesmo tempo funções de integração social, de legitimação e de dissimulação de uma ordem social existente" (I999, p. 65). 
Se considerada no quadro de uma evolução unidirecional - que, todavia, não deve ser vista nem aceita como inexorável ${ }^{4}$-, essa nova estratificação ou dualização em contexto de trabalho, que se pretende por vezes naturalizar como decorrência inevitável dos níveis diferenciados de educação e qualificação supostamente dependentes da exclusiva vontade e capacidade dos trabalhadores, terá necessariamente amplas implicações não apenas em termos de redefinição de vínculos e identidades pessoais e familiares, mas também em termos de ordem e coesão sociais. Como lembra Manuel Castells, uma das características do capitalismo informacional é a "tendência para aumentar a desigualdade e a polarização sociais" uma vez que se estabelece uma nova diferenciação entre o "trabalho autoprogramável e altamente produtivo", que supõe níveis mais elevados de educação e qualificação, e o "trabalho genérico" que, embora continue a existir e a ser necessário, se torna cada vez mais vulnerável, ou mesmo prescindível, porque, ao não exigir os mesmos níveis de educação e qualificação, permite mais facilmente dispensar (individualmente) os trabalhadores. Tudo isso se agrava, acrescenta o autor, não apenas porque a individualização do trabalho mina a organização coletiva e a solidariedade entre os trabalhadores, como também porque a desaparição gradual do EstadoProvidência torna mais difícil apoiar aqueles que acabam por perder o vínculo social não apenas como trabalhadores/produtores mas também como consumidores (cf. Castells, 1998, p.378). Acresce a tudo isto que a "responsabilização autoritária dos trabalhadores", como refere Emilio Taddei, tem também, em alguns países, uma tradução específica no campo das políticas sociais. Trata-se, muito sucintamente, de um novo cerceamento à segunda geração de direitos, que se traduz na obrigação de os desempregados participarem em programas de formação para o emprego, ou de aceitarem os empregos que lhe são propostos, sob pena de perderem os subsídios do Estado ${ }^{5}$. Esta substituição do welfare pelo agora designado workfare revela igualmente uma outra dimensão extremamente controversa das atuais políticas de educação e formação. Na nossa perspectiva, este é um espaço para o qual

4. Não aceitando a visão determinista que subentende que o caminho já está traçado pelas tecnologias da informação, erradamente "entendidas como forças atuantes autônomas do contexto sociocultural”, Ilona Kovács (1998d) contrapõe, a esse propósito, alguns argumentos interessantes para pensar as alternativas disponíveis.

5. E acrescenta ainda o autor: "O fantasma da perda de direitos sociais (e fundamentalmente da indenização para o desemprego) é o que obriga os desempregados a terem de aceitar trabalhos cada vez mais precários e sub-remunerados, para não perder os magros subsídios. As políticas de responsabilização autoritária dos trabalhadores funcionam como uma espada de 
confluem algumas conseqüências indesejadas das novas formas de organização do trabalho decorrentes da expansão e consolidação do capitalismo global/informacional e das conseqüências mais nefastas da ideologia neoliberal que se tornou hegemônica após a crise do Estado-Providência. Se os discursos oficiais apresentam a urgência e a inevitabilidade da realização de uma aprendizagem permanente para atender às exigências decorrentes dessas novas formas de organização e divisão do trabalho, sob pena de cada um de nós se tornar "incompetente para a competitividade" ${ }^{\prime}$, também os pressupostos do neoliberalismo que, como refere Pierre Bourdieu ( 1998), nos são impostos como óbvios mediante um eficaz trabalho de inculcação simbólica, apontam para o fato de ser impossível resistir às forças econômicas que elegem a produtividade e a competitividade como o fim último e único das ações humanas.

\section{A ENUNCIAÇÃO DE ALTERNATIVAS AO PENSAMENTO ÚNICO}

Ao mesmo tempo em que avança a globalização econômica e se desvanecem as utopias relativas às grandes narrativas anunciadoras de uma sociedade mais justa e igualitária (algumas, em grande parte, vinculadas à autonomia relativa do Estado-Nação e à forma política do Estado-Providência), os próprios críticos do neoliberalismo (alguns, mesmo, com percursos anteriores relacionados à tradição marxista e neomarxista) começam a aceitar que é pouco provável, a curto e médio prazos, inverter significativamente o rumo das mudanças em curso ou fugir das novas condicionantes megaestruturais. Nesse sentido, uma nova agenda teórica e política decorreria agora da necessidade de considerar de modo realista as exigências inerentes à competitividade econômica que confrontam países distintos com um mercado cada vez mais global, mas reafirmando, de forma sincrônica e politicamente empenhada, as exigências relativas à garantia de direitos sociais e econômicos fundamentais - aqueles que, por exemplo, as políticas mais radicais da chamada nova direita tentaram suprimir ou diminuir por serem, nesse quadro

Dâmocles sobre a cabeça dos mesmos. Esta concepção liberal-autoritária da 'aposta no trabalho' rompe com a visão solidária do desempregado tradicional vigente na Europa, em função da qual era considerado como uma vítima (e não como responsável), com quem a sociedade considera ter uma dívida, dado que é incapaz de lhe oferecer um emprego. $\bigcirc$ workfare necessita então, para ser legitimado, uma 'reatualização' no terreno filosófico, a qual se leva a cabo redefinindo os conceitos de justiça e de equidade" (Taddei, 1998, p. 349).

6. A expressão é de Gaudêncio Frigotto (s/d) "Cidadania e formação técnico profissional". Texto consultado na Internet (http://bve.cibec.inep.gov.br/). 
mais tecnocrático, percebidos como obstáculos para a sustentação das novas vantagens competitivas procuradas ${ }^{7}$.

Nesta nova agenda, a educação e a formação são evocadas como soluções fundamentais para, por um lado, preparar uma mão-de-obra qualificada que atenda às exigências da competitividade econômica e às mutações no sistema ocupacional e, por outro, para preparar indivíduos que, a partir de uma escolaridade básica bem-sucedida, sejam capazes de continuar a aprender e a incorporar novos conhecimentos que os mantenham menos vulneráveis aos processos de exclusão social. Com nuances importantes, que nem sempre são imediatamente identificáveis, têm aparecido trabalhos e documentos diversos que parecem convergir na defesa dessa prioridade; mas ela está longe de significar sempre o mesmo quando se analisam mais de perto os discursos produzidos, as razões evocadas ou as políticas propostas para a consecução. Começaremos por referir sucintamente um dos documentos elaborados por uma importante agência das Nações Unidas que, nessa década e sobretudo no âmbito dos países da América Central e do Sul, induziu um importante debate precisamente sobre o lugar da educação nas mudanças sociais e econômicas em curso, e que contém alguns postulados relativos à problemática em análise.

Desde o início dos anos 90, a Comissão Econômica para a América Latina Cepal - tem, em importantes relatórios setoriais, chamado a atenção dos governos latino-americanos para a urgente necessidade de considerarem a educação e o conhecimento como articuladores fundamentais do que designa como proposta para uma "transformação produtiva com eqüidade" (Cepal/Unesco, 1992). A expressão, de fato, exemplifica bem as articulações híbridas que são anunciadas como parte de um novo projeto: "a transformação produtiva e a sua compatibilização com a democratização política e a crescente eqüidade social". No projeto, a educação e o conhecimento são também percebidos como fatores essenciais por dois motivos: um deles diz respeito à pressão da competitividade global que, por uma razão idêntica à dos países capitalistas mais avançados, atinge também os países capitalistas menos desenvolvidos da América Latina; o outro é um motivo específico destes últimos, porque se espera que a educação e o conhecimento constituam igualmente

7. Como assinala o "livro branco" da Comissão Européia, "É necessário raciocinar cada vez mais em termos de vantagens competitivas e não já em termos de vantagens comparativas. As vantagens comparativas correspondem às dotações em fatores produtivos, tais como os recursos naturais, sendo por esse motivo algo rígidas. As vantagens competitivas decorrem de elementos mais qualitativos, sendo por esse fato largamente determinadas pelas estratégias das empresas e das políticas públicas" (Comissão Européia, 1994, p. 77). 
direitos de cidadania, e que sejam pilares fundamentais da nova fase de consolidação democrática que veio substituir, há pouco mais de uma década, os governos e regimes militares. Mais ainda, trata-se de procurar que, apesar das tensões que comportam as suas relações, a competitividade e a cidadania sejam condição uma da outra:

Nestas circunstâncias, é fundamental desenhar e pôr em prática uma estratégia para impulsionar a transformação da educação e da capacitação, e aumentar o potencial científico-técnico da região, tendo em vista a formação de uma cidadania moderna vinculada tanto à democracia e à eqüidade como à competitividade internacional dos países, e que torne possível o crescimento sustentado apoiado na incorporação e difusão do progresso técnico. Imaginar que a cidadania possa ter plena vigência sem um esforço efetivo em matéria de competitividade resulta, na década de noventa, tão infundado como supor que a competitividade - necessariamente de caráter sistêmico - pode sustentar-se com descompassos importantes no âmbito da cidadania. (Cepal/Unesco, 1992, p. 18, tradução nossa)

Pressupõem-se ainda, em outras passagens do documento, duas acepções distintas de competitividade: a "competitividade espúria", que deve ser rejeitada porque se baseia na depredação dos recursos naturais e na depreciação dos níveis salariais, e a "competitividade autêntica", que, ao contrário daquela, "se baseia na incorporação do progresso técnico e na elevação da produtividade e das remunerações", e que, "pelo seu caráter sistêmico requer um grau razoável de coesão social e de eqüidade". Trata-se assim de uma proposta relativamente otimista que não deixa, apesar disso, de reconhecer a "existência de tensões entre cidadania e competitividade" (idem, p. 24, 34, 18), e de ponderar uma série de possíveis entraves à desejada concretização dessas dimensões, tendo em conta, nomeadamente, as especificidades dos países latino-americanos em face dos países capitalistas mais avançados, quer em termos de desenvolvimento democrático e educacional, quer em termos de desenvolvimento do sistema produtivo.

Remetendo mais ou menos diretamente para o documento da Cepal, muitos outros trabalhos discutiram os pressupostos nele enunciados, retirando ilações diversas para as políticas a implementar em relação à educação básica (ver, entre outros, Paiva, Warde, 1994; Miranda, 1997; Shiroma, Campos, 1997). A este propósito, e precisamente num trabalho intitulado Cidadania e competitividade: desafios educacionais do terceiro milênio, embora deixe margem a contestação em outras passagens, uma conhecida autora brasileira defende:

Na maioria dos países da América Latina, entre eles o Brasil, o modelo educativo que serviu a uma etapa de desenvolvimento foi o de uma elite altamente educada e 
informada e de uma massa escolarizada apenas para dar conta das tarefas elementares de uma industrialização tardia e dependente. Esse modelo educativo foi abalado, na medida em que se esgotou o modelo econômico baseado na abundância de matéria-prima e de mão-de-obra desqualificada e barata, ao qual se associava. Neste sentido, pode-se mesmo afirmar que, dado o padrão desigual de desenvolvimento tanto no continente como um todo, como no interior de cada país, a preparação do conjunto da sociedade para incorporar os avanços tecnológicos, de modo a utilizálos para melhorar a qualidade de vida, é condição para evitar a ação de novos elementos de seletividade e desigualdade social. (Mello, 1993, p. 28)

Para além da sua referência às especificidades latino-americanas, constatase também em muitos outros trabalhos que a evocação simultânea da competitividade e da cidadania parece sobretudo decorrer da assunção otimista e pouco problematizada do que se supõe serem os efeitos positivos de uma generalização, dada como certa, do sistema de produção pós-fordista. No quadro de um novo sistema de produção baseado na especialização flexíve/, muito diferente do rígido sistema fordista de produção em massa, as empresas necessitariam de indivíduos com um novo perfil profissional. Ao contrário do trabalhador taylorista, sem ou com escassa escolarização e desapropriado da sua subjetividade, criatividade e autonomia, agora só haveria lugar para o trabalhador escolarizado, educado e qualificado, preparado para trabalhar em equipe, com capacidade de iniciativa e espírito crítico. Para alguns o desenvolvimento desses "atributos desejáveis" significa não apenas "um avanço considerável em relação ao trabalhador 'alienado', incapacitado (impedido, na realidade) de 'pensar a produção', característico do modelo fordista", mas significa também, mais uma vez, a possibilidade de fazer convergir as exigências do trabalho e as exigências da cidadania (Villela, Allen, Café, 1994). Nesse sentido,

...no contexto da reestruturação produtiva [...] impõe-se o fim da distinção entre estas duas esferas, principalmente porque a valorização das habilidades intelectuais implica o desenvolvimento das múltiplas potencialidades do homem, o que o habilita tanto para a cidadania como para o trabalho. (Fogaça, Silva apud Villela, Allen, Café, 1994, p. II)

Referindo-se a essas mudanças, escreve também J. Carlos Tedesco:

Deste ponto de vista analítico, as empresas modernas surgem como um paradigma de funcionamento baseado no pleno desenvolvimento das melhores capacidades do ser humano. Estaríamos perante uma circunstância história inédita em que as capacidades para o desempenho do processo produtivo seriam as mesmas que se 
exigem para o papel de cidadão e para o desenvolvimento pessoal. No sistema capitalista tradicional de produção em massa, pelo contrário, gerava-se um funcionamento paralelo, por vezes contraditório, entre, por um lado, as exigências da formação do cidadão e do desenvolvimento pessoal - em que as qualidades requeridas eram a solidariedade, a participação, a criatividade, o pensamento crítico e, por outro lado, as exigências da formação para o mercado de trabalho - disciplina, obediência, passividade, individualismo. Porém, nos novos modelos de produção, existe a possibilidade e a necessidade de pôr em jogo as mesmas capacidades exigidas para ambos os níveis pessoal e social. (1999, p. 58)

Seria possível continuar a enumerar e a citar um já amplo conjunto de trabaIhos e autores que, a partir de procedências disciplinares e políticas diferentes, têm abordado a questão da necessária convergência entre objetivos econômicos, como o da competitividade, e objetivos sociais e políticos, como o da cidadania, discutindo igualmente a centralidade da educação na articulação de ambos. Alguns desses autores, procurando pensar alternativas que vão além do pensamento único imposto pelo neoliberalismo econômico, aceitam discutir a validade de uma "terceira via". A esse propósito, o conhecido sociólogo Ralf Dahrendorf ( 1977), considerado um dos inspiradores das propostas do Partido Trabalhista inglês de Tony Blair (New Labour), tem defendido que "a competitividade não pode sacrificar a solidariedade", e chegou mesmo a escrever um pequeno livro no qual fala da "quadratura do círculo", isto é, da possibilidade de "tentar alcançar, na sua totalidade, três objetivos: o êxito econômico, a solidariedade social e a liberdade política" (Dahrendorf, 1996, p. 65-6) ${ }^{8}$. Um outro sociólogo contemporâneo, Alain Touraine, depois de um trabalho ( Carta aos socialistas) em que já criticava a tradicional "recusa das realidades econômicas" por parte da esquerda e a sua "indiferença à competitividade econômica", volta agora a lembrar a responsabilidade dos intelectuais, que não devem ficar apenas na denúncia, devendo antes pensar e apoiar alternativas para sair do liberalismo. Nesse sentido, reconhecendo ainda que a política de Tony Blair tem "o grande mérito de combinar objetivos econômicos e sociais", Touraine considera que ela adota, na realidade, como eixo o liberalismo, que corrige através de políticas sociais e que, por isso, não pode ele próprio deixar de propor uma via intermediária entre a antiga social-democracia e a terceira via, em que, para além da "prio-

8. Ainda que Ralf Dahrendorf seja também considerado um dos inspiradores das propostas do Partido Trabalhista inglês de Tony Blair (New Labour), o seu pensamento parece-nos, em muitos aspectos, claramente distinto do de Anthony Giddens, que é também considerado o principal ideólogo da chamada terceira via. Ver a este propósito, Giddens (1999) e também Blair (1998). 
ridade ao trabalho" e da valorização da "comunicação intercultural", um dos pontos essenciais é também mostrar que é preciso "devolver prioridade à inovação, à educação e à solidariedade" (Touraine, 1999, p. 136 e ss.).

\section{EXPLORANDO O CAMINHO: A DISCUSSÃO DE ALGUNS PRESSUPOSTOS}

\section{É sustentável o modelo liberal-produtivista?}

Maior aprofundamento de todas as questões aqui levantadas teria também de passar por outras reflexões, sobretudo aquelas que, vindo de autores igualmente empenhados em procurar alternativas ao pensamento único, não aceitam todavia que haja nesse debate postulados intocáveis, como o da competitividade. A esse propósito, Riccardo Petrella propõe mesmo que seria conveniente "proceder a uma forte campanha de desvalorização do imperativo da competitividade e dos numerosos indicadores que na hora atual constituem o abc do "pensamento econômico'" (Petrella, 1994, p. 87). Ao contrário daqueles que poderão pensar que a convergência da competitividade e da cidadania, até o momento, todavia, apenas retoricamente anunciada, já representa um novo consenso capaz de ultrapassar velhas dicotomias e objetivos inconciliáveis, as perspectivas mais realistas lembram que "uma das grandes fraquezas da competitividade advém do fato de ser claramente incapaz de reconciliar justiça social, eficiência econômica, preservação ambiental, democracia política e diversidade cultural, no mundo em que vivemos". Por isso, conclui: "Fica claro que temos que procurar uma alternativa mais eficiente, mais efetiva e mais segura" (Grupo de Lisboa, 1994, p. 156).

No mesmo sentido, Bourdieu insiste em denunciar a operação de mistificação que consiste em separar o econômico do social pelo cálculo da eficácia e rentabilidade financeiras, ignorando sistematicamente os custos sociais. Às decisões tomadas nessa base opõe em alternativa uma economia da felicidade que leve em conta os ganhos e custos individuais e coletivos associados às opções políticas em confronto (Bourdieu, 1998, p. 39, 50) ${ }^{9}$. Mais ainda, se a competitividade, segundo

9. Em consonância com este sociólogo, e valorizando a "competitividade com rosto humano", o relatório Para uma Europa dos Direitos Cívicos e Sociais, elaborado pelo Comité de Sábios presidido por Maria de Lurdes Pintasilgo, acentua a urgência de "introduzir o princípio segundo o qual todas as políticas européias devem ser objeto de um estudo de impacto em termos de coesão social", bem como refere ser necessário "lançar um programa de trabalho no domínio da política social européia e evidenciar os custos da não-Europa social" (Comité de Sábios, 1996, p. 2, 3, 7, 29). 
o modelo liberal-produtivista assente na guerra de todos contra todos, é hostil à consideração das necessidades e sofrimento humanos, exibe a mesma virulência agressiva em face do planeta que temporariamente partilhamos. De acordo com Alain Lipietz o modelo de "flexibilização" que, ao longo dos anos 80 , foi adotado por diversos países do mundo, dispensando os compromissos sociais, ignora qualquer exigência de responsabilidade ecológica, não constituindo, por isso, uma via de desenvo/vimento sustentável. Em alternativa, argumenta o autor, há lugar para defender uma via de competitividade assentada na progressiva "unificação das regras sociais e das regras de proteção do ambiente", a par da unificação dos mercados. Nesse sentido, a introdução de reformas profundas antitaylorianas na organização do trabalho, acompanhadas de aumento do tempo livre como contrapartida da parte dos trabalhadores para o seu maior envolvimento "em prol da qualidade e da produtividade", bem como a negociação de compromissos em torno da estabilidade de empregos, rendimentos e carreiras, permitiriam fazer esperar "a pacificação da concorrência de todos contra todos engendrada pelo liberal-produtivismo", que a prazo se revela insustentável ${ }^{10}$. Essa, para além de não ser a única via para a competitividade, como, segundo o mesmo autor, é evidenciado pelos modelos seguidos por diferentes países, exclui quer o desenvolvimento da maior parte da população do planeta, quer a inversão das tendências potenciadoras de uma crise ecológica global (cf. Lipietz, 1995, p. 47-55).

\section{Questionando a visão pós-fordista: uma nova (e feliz) correspondência?}

Uma outra perspectiva que interessa problematizar é se o pressuposto otimista da generalização de um modelo de produção pós-fordista, identificado freqüentemente como de especialização flexível, traduz a celebração de uma auspiciosa e, finalmente, realizável oportunidade de fazer da produção e do trabaIho lugares de exercício e desenvolvimento de capacidades e valores convergentes com aqueles que animam generosas concepções e avançadas práticas de cidadania em outros espaços da vida social. Uma resposta positiva tornaria possível, de acordo com estas visões do futuro, concretizar pela primeira vez na história uma con-

10. O autor defende que o Ato Único Europeu e o Tratado de Maastricht inauguraram uma nova era européia em que, pela primeira vez, não ocorreu em simultâneo a unificação dos mercados e das regras sociais, constituindo a fonte de "o dumping social, o dumping ecológico, o dumpingfiscal" (Lipietz, I995, p. 2). Pierre Bourdieu sublinha igualmente que é a concorrência entre os trabalhadores europeus, alimentada pela discrepância de regras atrás assinalada, que constitui a principal arma para "um regresso a um capitalismo selvagem" (1998, p. 45). 
cepção e um projeto de educação em que coincidiriam a formação para a vida de trabalho, nas suas dimensões pessoal, profissional e organizacional, e para a participação democrática na vida coletiva. Melhor dizendo, a preparação para o trabalho assentar-se-ia no desenvolvimento do mesmo conjunto de disposições, orientações e valores que a educação para o exercício de cidadania. Pelo que a articulação educação, cidadania e competitividade resultaria, quase naturalmente, de supostas mudanças profundas e generalizadas no funcionamento da economia e da organização da produção e do trabalho.

Na nossa perspectiva, tal assunção torna-se, no entanto, muito problemática quando atentamos num conjunto muito vasto de estudos e argumentos que defendem e evidenciam o caráter diversificado e muito desigual das tendências em curso nos domínios referidos. Não só parecem desenhar-se diferentes modos de inserção das economias nacionais na economia global, como tais opções se articulam com o desenvolvimento de modelos de produção distintos, uns apresentando traços próximos de modalidades neofordistas, outros suscitando a emergência do que pode vir a constituir-se como novas configurações produtivas (cf. Boyer, 1997). Esses trabalhos convergem não apenas para sublinhar a impossibilidade de antecipar se um dado modelo de produção virá a tornar-se dominante, como também chamam a atenção para o caráter infundado (ou mesmo visionário), e, por vezes, política e ideologicamente suspeito, daquelas leituras da realidade baseadas na possibilidade de generalização de modalidades predefinidas e predeterminadas de organização da produção e do trabalho" '.

Assim, de acordo com investigações e pontos de vista mais cautelosos e empiricamente sustentados, a organização da economia, da produção e do trabatho apresentam uma complexidade, diversidade e instabilidade tais que abrem espaço para a definição de projetos e estratégias de atuação por parte dos diversos atores sociais, susceptíveis de influenciar decisivamente os processos em curso. Mas

I I. Entre nós dispomos já de um apreciável conjunto de trabalhos que sustentam o caráter infundado de tais avaliações e perspectivas futuristas celebratórias de um (suposto) pós-fordismo reinante (cf. Kovács, Castillo, 1998; Kovács, 1998; Stoleroff, Casaca, 1996; Stoleroff, Casaca, 1998; Kovács, 1998b). Pelo contrário, salientam llona Kovács e Juan José Castillo, "há diversos modelos de produção de acordo com as situações sociais e históricas concretas, podendo coexistir diversos modelos num determinado país, setor, região e até numa mesma empresa" sublinhando "a urgência de mostrar a distância que separa os discursos e as práticas e de identificar as tendências de evolução com base na análise de situações e práticas concretas" (Kovács, Castillo, 1998, p. 2; cf. também, na mesma obra, os capítulos 2 e 3 assinados por Castillo). 
apenas o conhecimento e a prática reflexivos podem contribuir para orientar opções congruentes com os fins desejados.

\section{Equívocos e omissões de um consenso simples}

\section{Educação e competitividade: uma equação complexa}

Num texto intitulado "Can Education do it alone?" Henry Levin e Carolyn Kelley defendem que a educação pode contribuir decisivamente para muito daquilo que lhe é exigido, mas apenas se as condições necessárias para tal forem proporcionadas; isto é, "apenas se a educação se traduzir em oportunidades" poderá efetivar o seu potencial. Dito de outro modo, "a educação apenas pode contribuir para aumentar a produtividade se houver oportunidades de emprego para trabalhadores mais produtivos". A perspectiva de que a educação pode, por si mesma, resolver problemas de produtividade e competitividade da economia, ignorando outras condições necessárias - novos investimentos, novos métodos de organização do trabalho, novas abordagens de gestão - tem como conseqüência, segundo os mesmos autores, que as empresas "são reforçadas nas suas crenças de que o principal obstáculo ao seu sucesso é a pobre educação da força de trabalho", distorcendo assim as políticas nacionais e industriais para direções incapazes de favorecer a produtividade nacional (cf. Levin, Kelley, 1997, p. 240, 245). Nesse sentido, coloca-se a questão de se saber em que condições a competitividade das economias pode ser potencializada pela difusão de elevados níveis de educação e formação. Uma boa parte da investigação disponível defende a importância decisiva de as políticas econômicas e industriais serem orientadas para favorecer quer um volume e composição adequados de investimento, quer alterações profundas na organização da produção e do trabalho. Ou seja, segundo os autores, a ausência ou subdesenvolvimento de tais processos tornam ilusórias, ou mesmo perversas, as expectativas criadas acerca dos benefícios decorrentes de uma força de trabalho mais educada. Argumentando num sentido convergente, Kovács sublinha a relação de mútua sustentação entre as políticas públicas, as estratégias patronais e sindicais, os modos de organização do trabalho e a educação e formação na criação de condições que viabilizem o que designa como novo paradigma produtivo, orientado não só para a competitividade da economia como para a democratização da vida social, nomeadamente na esfera do trabalho (cf. Kovács, 1998, 1998a, 1998c, 1998d) ${ }^{12}$.

12. Ilona Kovács propõe uma concepção de novo paradigma produtivo que enfatiza tanto a flexibilidade no que respeita a produtos, mercados, tecnologias e trabalho como à natureza 
Tendo-se consolidada a perspectiva de que as formas de organização do trabalho condicionam decisivamente as oportunidades de mobilização e desenvolvimento dos saberes e competências individuais e coletivos dos trabalhadores, alguns autores defendem que no interior das organizações têm lugar processos bloqueadores ou propiciadores da aprendizagem que são em grande medida dependentes do tipo de gestão e das características das situações de trabalho. A esse propósito, por exemplo, são freqüentes, em relação à indústria portuguesa, as referências a "processos de antiaprendizagem", a "perdas de investimento em formação profissional associadas a determinadas formas de organização do trabaIho mais tradicionais" (Moniz et al., 1998, p. 64-5; cf. também Kovács, 1998d) ou mesmo a "regressões culturais" ou à dissipação do "potencial humano adquirido no sistema de ensino" (Pinto, 1994, p. 178, 1997, p. IV; cf. também Afonso, 1999, p. 24-6).

Parece, assim, que a aparente linearidade da ligação entre educação, desenvolvimento econômico e competitividade apresenta meandros e contornos bem mais complexos - pelo que, a desvalorização sistemática das mediações e condições que qualificam aquela relação produz não só um profundo enviesamento da interpretação da realidade como pode igualmente resultar num equívoco perigoso do ponto de vista das suas conseqüências sociais.

\section{Educação, empregabilidade e exclusão social}

A prioridade à educação e formação tem sido igualmente convocada como via para contrariar a vulnerabilidade dos indivíduos a processos de exclusão social, sobretudo mediante a designada promoção da sua empregabilidade.

Apesar de importante, não abordaremos a discussão do(s) sentido(s) assumido(s) pela temática da exclusão (e inclusão) social - quer no domínio da investigação, quer no debate e na intervenção políticos -, nem do conjunto de significados associados ao termo empregabilidade. Tentaremos apenas interrogar os limites inerentes ao pressuposto de que há uma relação essencial de dependência, no sentido referido e com caráter unívoco, entre os processos sociais condensados sob aquelas designações.

das "organizações flexíveis, descentralizadas e participativas com recursos humanos qualificados e polivalentes". Defende que os sistemas antropocêntricos de produção constituem "uma alternativa para a Europa" "quer do ponto de vista da valorização dos recursos humanos e da melhoria da qualidade de vida (no trabalho e em geral) quer do ponto de vista da melhoria da competitividade das empresas" (Kovács, 1998b, p. 75, I998c, p. 93-II I). 


\section{(Des)emprego e distribuição de renda}

A perspectiva que acabamos de enunciar e os programas de ação nela inspirados não permitem confrontar, entre outros, o problema da distribuição de renda em sociedades em que o desemprego e/ou a degradação do emprego constituem opções políticas viabilizadas e apoiadas, quer pelos Estados quer pelas empresas que lhes dão seqüência, para fomentar o crescimento e a competitividade das economias (cf. Rhodes, 1991, 1995; Streeck, 1996; Brown, Lauder, 1997).

Nesse contexto, o funcionamento do mercado de emprego não só exclui uma parte significativa da população como não proporciona as condições mínimas de sobrevivência a muitos daqueles que aí estão integrados, nomeadamente em Portugal e na União Européia, mas também, por exemplo, nos Estados Unidos da América ${ }^{13}$.

A consciência dessa prioridade de confrontar o problema da distribuição de renda nas nossas sociedades - em que a insegurança econômica, efetiva ou potencial tornou-se um constrangimento decisivo para uma parte significativa da população tem conduzido à insistência crescente, por parte de analistas e protagonistas envolvidos no debate sobre as políticas sociais no contexto europeu, a favor da institucionalização de uma renda básica universal que assegure condições de vida dignas, a autonomia e solidariedade inerentes à realização de uma cidadania substantiva (cf., por exemplo, Brown, Lauder, 1997; Standing, 1997, 2000; Silva, 1999).

\section{Politicas de (des)emprego}

Os debates sobre o desemprego, com forte expressão, por exemplo, na União Européia, a partir dos anos 80, têm desembocado sistematicamente em propostas orientadas para a intervenção do lado da oferta de mão-de-obra. Neste sentido, numa primeira fase, as medidas defendidas visaram à alteração das condições de utilização da força de trabalho, enfraquecendo a capacidade de negociação dos trabalhadores sobretudo pela desregulação/flexibilização do mercado de emprego (cf. Rhodes, 199I; Standing, 1997). Mais recentemente, têm sido preconizadas iniciativas que envolvem a gestão do contingente de desempregados, mediante chamadas políticas ativas de emprego, orientadas para determinadas categorias sociais e centradas na formação e criação de incentivos ao emprego e autoemprego.

13. Conferir, entre outros, Almeida et al. (1992, p. 7I-5, I04-5), Costa (1998, p. 39-45), Castells (1997, 1998); consultar também, por exemplo, edições do jornal Público 25 fev. 1999, p. 34; 29 nov. 1999, suplemento Economia, p. 6-7). 
Reconhecendo os efeitos positivos das políticas ativas de emprego - no que toca, por exemplo, à disseminação de qualificações ou à suspensão temporária do desemprego para os grupos envolvidos - alguns analistas chamam a atenção para outras características marcantes da atual situação. Do ponto de vista desses autores, tais debates e opções têm sido muito eficazes na promoção da aceitação generalizada de altas taxas de desemprego e de insegurança econômica, possuem um elevado potencial para produzir a estigmatização e a coerção de segmentos marginais ou excluídos do mercado de emprego, bem como para pressionar no sentido da baixa de salários e condições de trabalho dos empregados. Além disso, a ocorrência de efeitos de substituição, identificados em relação a algumas dessas medidas em diversos países, sugere que as taxas de colocação verificadas podem repercutir tanto na redução do desemprego como na alteração das categorias que compõem o contingente de desempregados (cf. Standing, 1997, p. 203-15). Assim, as políticas de promoção do emprego, seguidas nomeadamente na União Européia - quer aquelas explicitamente orientadas para a flexibilização da utilização da força de trabalho, quer as intervenções que visam ao envolvimento de desempregados em modalidades de formação ou de atividades remuneradas - parecem merecer um exame crítico sério, que equacione o seu potencial para distribuir o rendimento ou o desemprego, e para promover a justiça ou a desigualdade e exclusão sociais.

\section{Empregabilidade, qualificação e emprego}

A ênfase na promoção da empregabilidade dos indivíduos, mormente por meio da expansão de oportunidades de acesso à educação e formação, assenta-se no pressuposto de que ao desemprego se encontra associado um déficit de qualificação que, sendo confrontado e resolvido, se reflete na anulação ou diminuição desse mesmo desemprego ${ }^{14}$. Ora, grande parte da investigação na área indica que a relação entre formação, qualificação e emprego envolve não só os atributos do trabalhador e as características do posto de trabalho (condicionadas pela organização do trabalho) como as relações de poder que se jogam no mercado de emprego entre assalariados e empregadores, entre grupos de trabalhadores, dependendo ainda da concorrência entre candidatos ao emprego. Dispomos de um imenso vo-

14. Não estão em causa os esforços, programas e políticas orientados para beneficiar a formação dos indivíduos e grupos sociais desfavorecidos quanto aos níveis de escolarização e qualificação de que dispõem, já que, obviamente, se trata de minorar uma fonte de desigualdade a que estão sujeitos. $\bigcirc$ que se questiona é a concepção de que o desemprego e a empregabilidade podem ser seriamente confrontados mediante respostas educativas. 
lume de investigações que reiteradamente evidenciam o significado desta e de outras mediações e interações (consultar a respeito: Tanguy, 1986, cap. 3, Alaluf, 1986, Rainbird, 1995, Rosa, 1996, Correia, 1996, p. 36-9, I 13-6; 1998, p. I61-3, Grácio, 1997, cap. 6, Letelier, 1999).

Defender uma política de acesso ao emprego assente prioritariamente na promoção da empregabilidade dos indivíduos, pelo seu envolvimento em mais educação e formação, significa descurar o fato de que, por exemplo, o nível educacional dos trabalhadores que acedem a um dado emprego varia, dentro de alguns limites, conforme o grau de escolarização da população, em particular daqueles que se constituem como candidatos, efetivos ou potenciais, à categoria ocupacional em apreço ${ }^{15}$. Assim sendo, a prioridade à promoção da empregabilidade pela elevação dos níveis de ensino e formação, sem um esforço equivalente orientado para a expansão de empregos qualificados, parece ter probabilidades significativas de produzir, entre outras, duas conseqüências igualmente contraproducentes: o adiamento sine die do acesso ao emprego daqueles que se encontram no final da fila de espera, qualquer que seja o seu nível de formação, mas também a sobrequalificação dos empregados, aliada ao desemprego de diplomados, por exemplo, do ensino secundário e superior (ver a respeito Nunes, 1998, especialmente os capítulos assinados por João Sedas Nunes e por José Machado Pais; OCDE, 1998; Kovács, 1998d). Tais conseqüências evidenciam os limites inerentes à omissão ou insuficiência de políticas que promovam a empregabilidade também pela criação de empregos que concomitantemente favoreçam a organização da produção e do trabalho

15. Conferir, por exemplo, o estudo de Letelier, comparando dados relativos a Santiago do Chile e São Paulo, no Brasil, em 1995. A autora analisa os níveis de escolarização que caracterizam a população economicamente ativa numa e noutra região e aqueles que se verificam em diversas categorias profissionais (motoristas, telefonistas e operadoras de telecomunicações, enfermeiras, parteiras, eletricistas, operadores de som, despachantes e carteiros) e setores como a indústria metalomecânica. Em face da divergência encontrada entre os níveis de formação dos trabalhadores, em cada uma daquelas regiões, para uma mesma ocupação e/ ou setor de atividade, a socióloga afirma que "a relação entre escolaridade e inserção no mercado de trabalho está determinada pelo perfil educacional geral alcançado pela sociedade, mais do que pela demanda de qualificação oriunda do mercado de trabalho" (Letelier, 1999, p. 136-7). Em Portugal, e relativamente ao setor da construção civil, Madureira Pinto assinala que "mais de $70 \%$ do pessoal com estatuto de 'encarregado, chefe de equipe ou contramestre' (...) têm, no máximo, quatro anos de escolaridade. Já na categoria dos 'praticantes e aprendizes', e como conseqüência do fenômeno de extensão da escolarização junto das camadas mais jovens da população portuguesa, tem aumentado regularmente a proporção dos que possuem pelo menos o $6^{\circ}$ ano de escolaridade (de 24\%, em 1982, passaram para quase 50\%, em 1993)" (Pinto, 1999, p. 28, grifos nossos). 
fundamentada na valorização dos recursos humanos (cf. Kovács, I998d, p. 76-8I; Pinto, 1999, p. 29, 37) ${ }^{16}$.

Torna-se, por isso, necessário discutir em que condições a expansão de oportunidades de educação e formação pode contribuir para contrariar o desenvolvimento de novas desigualdades sociais e de processos de exclusão social. $\bigcirc$ acesso ao emprego para todos parece não ser viável sem a promoção de políticas de criação e partilha de empregos. Mas a possibilidade de estas conduzirem a maior justiça social depende de novos compromissos sociais. Analistas como Lipietz ( 1995), Santos ( 1998) e Castel ( 1998) convergem na defesa da perspectiva de que a precariedade dos direitos sociais, associada à desregulação do mercado de emprego e à opção por políticas agressivas de recursos humanos (cf. Kovács, 1998e, p. 72-5), por parte das empresas, contribui para inviabilizar a construção de uma base alternativa para a solidariedade, justiça e coesão sociais.

\section{Outras dimensões sociais e culturais das politicas de educação e formação}

Constitui um dado adquirido que os indivíduos e os diferentes grupos sociais beneficiam-se de modo muito assimétrico da expansão de oportunidades de educação e formação, dada a desigualdade de condições em que estão colocados para aproveitar dos bens e recursos culturais e simbólicos. Algumas condicionantes são por demais conhecidas e podem ser sumariamente consideradas.

Por um lado, a mobilização para a educação e a formação apenas emerge e se consolida se os indivíduos tiverem garantidas quer a segurança econômica, quer a satisfação das necessidades e condições básicas de vida (cf. Brown, Lauder, 1997; Kovács, 1998d). A precariedade, a incerteza e a pobreza dificultam um envolvimento

16. A propósito da Cimeira Extraordinária de Lisboa sobre o Emprego, no âmbito da Presidência Portuguesa do Conselho Europeu, António Guterres, numa entrevista recente, insistiu sobre "o problema estrutural que tem a ver com a qualificação das pessoas e a qualidade do emprego" bem como a necessidade, em Portugal, de "aumentar a taxa de emprego (...) desenvolver a aprendizagem ao longo da vida (...) modernizar a organização do trabalho para que as pessoas possam produzir mais e melhor e com mais satisfação" (Guterres, 2000, p. 20-I). Essa abordagem mais global - se for traduzida, de forma consistente, em políticas e esforços coletivos dos vários atores envolvidos e incidindo nas diferentes dimensões e vetores assinalados - pode apresentar um potencial acrescido para tornar possível a articulação entre a expansão da educação e a promoção da cidadania, se, simultaneamente, a qualidade for desenvolvida como cidadania no emprego. Nesse sentido, as perspectivas avançadas por António Guterres na entrevista permitem confrontar alguns dos limites inerentes às abordagens, mais redutoras e mistificadoras, exclusiva ou principalmente centradas em propostas de promoção da empregabilidade mediante a qualificação da força de trabalho. 
significativo das crianças, jovens e adultos em percursos de formação prolongados e consistentes, pelo que apenas por inaceitável ingenuidade ou má-fé se podem alimentar expectativas de aqueles retirarem benefícios significativos e generalizados da expansão de oportunidades de educação e formação sem lhes serem garantidas a segurança material e condições de vida dignas.

Por outro lado, se "a educação não pode compensar a sociedade" (Bernstein, 1982), a forma e conteúdo que a educação assume são decisivos para que a generalização do acesso a modalidades e níveis de formação se traduza por uma distribuição eqüivalente dos recursos culturais e diplomas a estes associados (cf. Bernstein, 1996, 1998). Nesse sentido, uma política social de expansão das oportunidades educacionais e de formação terá de ser construída também como uma política cultural de sentido democrático. Nessa persp ectiva, torna-se crucial a definição de quais os saberes e práticas valorizados ou excluídos e de como estes se relacionam com as identidades desenvolvidas ou reprimidas por intermédio da educação (cf., entre outros, Young, 1982, 1989; 1998; Stoer, 1994; Cortesão, Stoer, 1996). A produção institucionalizada de uma ampla gama de desigualdades e exclusões culturais e sociais por intermédio do ensino e formação não autoriza abordagens voluntaristas e superficiais, ainda que bem-intencionadas, que ignorem as dimensões político-culturais da educação sublinhadas por décadas de experiências e de investigações.

A prevalência entre nós de um currículo escolar que persiste em vincar fronteiras, hierarquias e dicotomias entre formas e áreas de conhecimento, saberes e práticas sociais, e em desconhecer a pluralidade de universos existenciais e culturais dos públicos a que se destina constitui-se como exemplo tristemente incontornável dos limites de uma política de expansão da educação mutilada no seu potencial de afirmação do pluralismo e dos direitos culturais (cf., entre outros, Stoer, Araújo, 1992; Stoer, Cortesão, 1999).

Assume, ainda, particular importância a natureza posiciona/dos bens e recursos educativos formalmente certificados, como característica decisiva associada aos processos de escolarização que não pode deixar de ser enfrentada por qualquer política orientada para valorizar os efeitos e as dimensões distributivos da expansão de oportunidades de educação e formação (cf. Dale, 1994, p. 120-2). Com efeito, desde os trabalhos de Randall Collins (1977, 1979) ou Bourdieu (1979) - para citar apenas alguns dos mais importantes - que conhecemos o caráter mediado e relativo do valor assumido pelos graus e credenciais escolares. Esse valor não só é definido no interior de lutas concorrenciais, sobretudo entre grupos sociais com inte- 
resses divergentes quanto à abertura ou restrição da sua distribuição, como é objeto de estratégias de distinção que vão no sentido de produzir novos e sutis mecanismos de estratificação dos bens associados à educação e formação (Bourdieu, 1979). O conhecimento de que os sistemas educativo e formativo se constituem também como agências de distribuição de recursos culturais e simbólicos cujo valor social depende de relações de poder entre grupos sociais e da sua capacidade relativa para influenciar os resultados destes confrontos, obriga a colocar o problema posicional no centro do debate sobre educação e cidadania (cf. Brown, Lauder, 1997).

A difusão alargada de um dado nível de escolarização e formação apresentará limites óbvios, quanto à concomitante distribuição dos benefícios sociais e materiais a ele associados, se for acompanhada de formas, mais ou menos sutis ou explícitas, de distinção e estratificação entre os seus beneficiários (Bourdieu, 1979; Bourdieu, Champagne, 1992). Tais mecanismos de diferenciação, dentro de um mesmo nível de formação generalizadamente difundido, podem decorrer da criação de percursos, diplomas ou instituições cuja orientação para (ou utilização por) determinados grupos sociais estabelece discriminações, vantagens e assimetrias entre públicos formalmente beneficiários das mesmas ou de eqüivalentes oportunidades de educação e formação.

Não podem, assim, deixar de ser objeto de profunda reflexão os estudos e análises que chamam a atenção para a incontornável responsabilidade do Estado na definição das regras que garantam, a todos e a cada um, oportunidades justas e reais de desenvolver o seu potencial e de se beneficiar dos recursos e bens culturais e simbólicos proporcionados pelos sistemas de ensino e formação (cf. Brown, Lauder, 1997).

A responsabilização dos indivíduos pela sua formação, independentemente das condições em que se encontrem, a institucionalização de mecanismos de escoIha e de liberalização na educação - que criam novos espaços para o exercício de estratégias de distinção por parte dos grupos mais poderosos - são alguns dos processos sociais freqüentemente associados à produção de novas e profundas desigualdades e exclusões sociais (cf. Kovács, 1998d, p. 78-83; Brown, 1997). Desse modo, a credibilidade e o sucesso de um programa político que articule a ampliação de oportunidades de educação e formação e a afirmação da cidadania dependerão do modo como, em simultâneo, for efetivamente confrontado o problema político inerente ao valor posiciona/ dos bens educativos. 


\section{EDUCAÇÃO E FORMAÇÃO: NOVO PAPEL NA ARTICULAÇÃO ENTRE CIDADANIA E COMPETITIVIDADE?}

A investigação e análise disponíveis parecem sustentar a perspectiva de que é possível uma via de desenvolvimento humana, social e ecologicamente sustentável, distinta do modelo de competitividade liberal-produtivista baseada em novos e mais vastos compromissos sociais que associem a negociação de regras sociais e de proteção do ambiente à unificação dos mercados.

Por outro lado, a organização da economia, da produção e do trabalho apresenta uma complexidade e diversidade de configurações, dinâmicas e tendências que sugerem estarmos em presença de um processo em que emergem, se confrontam e podem vir a consolidar-se diferentes modelos, implicando formas alternativas de mediação dos conflitos e interesses sociais.

Nesse contexto, a prioridade à ampliação das oportunidades e à elevação dos níveis de educação e formação como via para consolidar e desenvolver os direitos de cidadania e para fomentar a competitividade das economias parece poder constituir-se em agenda política e teórica digna de crédito, se forem igualmente viabilizadas políticas econômicas, industriais e de emprego assentes na valorização do trabalho qualificado e na criação e partilha de empregos com base numa nova articulação de direitos e compromissos sociais.

Do mesmo modo, o conhecimento já consolidado nas Ciências Sociais sobre a educação sugere que a realização daquele potencial depende ainda da efetiva confrontação, por meio de políticas sociais e educacionais, de tensões e problemas inerentes à distribuição da renda (garantindo as indispensáveis segurança material e condições de vida dignas), à natureza posiciona/dos bens e recursos educacionais e remete para uma dimensão do seu valor que resulta do modo como influencia a posição social do seu detentor, mais do que da importância instrumental ou material que tem para ele. Esse valor social dos bens e recursos educacionais é variável, muitas vezes não coincidente com o seu valor formal, dependendo do modo como são estratificados entre si; assim, a sua posse posiciona os seus detentores numa escala hierárquica. 


\section{REFERÊNCIAS BIBLIOGRÁFICAS}

AFONSO, A. J. Educação básica, democracia e cidadania: dilemas e perspectivas. Porto: Afrontamento, 1999.

ALALUF, M. Le Temps du labeur. formation, emploi et qualification en sociologie du travail. Bruxelas: Éditions de l'Université de Bruxelles, 1986.

ALMEIDA, J. F. et al. Exclusão social: factores e tipos de pobreza em Portugal. Oeiras: Celta, 1992.

ANTUNES, F. Uma leitura do "Livro Branco" (sobre "crescimento, competitividade e emprego") do ponto de vista da educação. Educação, Sociedade \& Culturas, n. 6, p. 93-I I3, 1996.

BECK, U.; GIDDENS, A.; LASH, S. Reflexive modernisation. Cambridge: Polity Press, 1994.

BERNSTEIN, B. A Educação não pode compensar a sociedade. In: GRÁCIO, S.; STOER, S. R.; MIRANDA, S. (orgs.). Sociologia da educação ll:a construção social das práticas educativas. Lisboa: Livros Horizonte, 1982. p. 19-31.

. A Estruturação do discurso pedagógico: classe, códigos e controle. Petrópolis: Vozes, 1996. 1998.

.Pedagogia, control simbólico e identidad: teoría, investigación y crítica. Madrid: Morata,

BLAIR, T. La Tercera vía. Madrid: El Pais, Aguilar, 1998.

BOURDIEU, P. Contrafogos. Oeiras: Celta, 1998.

. La Distinction: critique sociale du jugement. Paris: Les Éditions de Minuit, 1979.

BOURDIEU, P.; CHAMPAGNE, P. Les Exclus de l'interieur. Actes de Recherche en Sciences Sociales, n. 9I-2, p. 7I-5, 1992.

BOYER, R. How does a new production system emerge? In: BOYER, R.; DURAND, J.-P. After fordism. Londres: Macmillan Press, 1997. p. I-63.

BROWN, P. Cultural capital and social exclusion: some observations on recent trends in education, employment and the labour market. In: HALSEY, A. H. et al. (orgs.). Education: culture, economy, society. Oxford: Oxford University Press, 1997. p. 736-49.

BROWN, P.; LAUDER, H. Education, globalization and economic development. In: HALSEY, A. H. et al. (orgs.). Education: culture, economy, society. Oxford: Oxford University Press, 1997. p. 172-92.

CASTEL, R. De l'intégration à la precarité: le "grand intégrateur" en péril? Un entretien avec Robert Castel (par Christine Fournier). Formation: emploi, n. 62, p. 87-93, 1998. 
CASTELLS, M. La Era de la información: economía, sociedad y cultura. Madrid: Alianza, 1997. v. I: La Sociedad Red.

. La Era de la información: economía, sociedad y cultura. Madrid: Alianza, 1998. v. 3: Fin de Milenio.

CEPAL, UNESCO. Educación y conocimiento: eje de la transformación productiva con equidad. Santiago de Chile: Publicación de las Naciones Unidas, 1992.

COLLINS, R. The Credencial society. New York: Academic Press, 1979.

. Functional and conflict theories of educational stratification. In: KARABEL, J.; HALSEY, A. H. (orgs.). Power and ideology in education. New York: Oxford University Press, 1977. p. 1 | 8-37

COMISSÃO EUROPÉIA. Crescimento, competitividade, emprego: os desafios e as pistas para entrar no século XXI. (Livro Branco). Luxemburgo: Serviço das Publicações Oficiais das Comunidades Européias, 1994.

. Ensinar e aprender. rumo à sociedade cognitiva. "Livro Branco" sobre educação e formação. Luxemburgo: Serviço das Publicações Oficiais das Comunidades Européias, 1995.

COMITÉ DE SÁBIOS. Para uma Europa dos direitos cívicos e sociais. relatório do Comité de Sábios. Bruxelas, 1996. (documento policopiado).

CORREIA, J. A. Para uma teoria crítica em educação. Porto: Porto Editora, 1998.

. Sociologia da educação tecnológica. Lisboa: Universidade Aberta, 1996.

CORTESÃO, L.; STOER, S. R. A Interculturalidade e a educação escolar: dispositivos pedagógicos e a construção da ponte entre culturas. Inovação, n. 9, p. 35-5I, 1996.

COSTA, A. B. Exclusões sociais. Lisboa: Fundação Mário Soares, Gradiva, 1998.

DAHRENDORF, R. As pessoas querem riqueza mas também solidariedade: entrevista. Jornal Público, p. 22-3, 13 nov. 1997.

. A Quadratura do círculo: bem-estar económico, coesão social, liberdade política. Lisboa: Edições 70, 1996.

DALE, R. A Promoção do mercado educacional e a polarização da educação. Educação, Sociedade \& Culturas, n. 2, p. 109-39, 1994.

FOGAÇA. A.; SILVA, L. C. Educação básica e reestruturação produtiva. Perspectivas da Economia Brasileira, v. 2, 1993.

FRIGOTTO, G. Cidadania e formação técnico profissional. Disponível em http:// bve.cibec.inep.gov.br 
GIDDENS, A. Para uma terceira via. Lisboa: Presença, 1999.

GRÁCIO, S. Dinâmicas da escolarização e das oportunidades individuais. Lisboa: Educa, 1997.

GRUPO DE LISBOA. Limites à competição. 2. ed. Lisboa: Publicações Europa-América, 1994.

GUTERRES, A. A Qualificação é a chave (entrevista assinada por Álvaro Mendonça; Fátima Azevedo; Rui Nunes). Economia Pura. Tendências e Mercados, n. 2 I , p. I 8-22, 2000.

HUGHES, C.; TIGHT, M. The Myth of the learning society. British Journal of Educational Studies, v. 43, n. 3, p. 290-304, 1995.

KOVÁCS, I. Da Controvérsia sobre os novos modelos de produção. In: KOVÁCS; I., CASTILLO, J. J. Novos modelos de produção: trabalho e pessoas. Oeiras: Celta, 1998. p. 5-24.

. Participação e competitividade. In: KOVÁCS, I.; CASTILLO, J. J. Novos modelos de produção: trabalho e pessoas. Oeiras: Celta, 1998a. p. II5-30.

. Requisitos de ensino e de formação profissional. In: KOVÁCS, I.; CASTILLO, J. J. Novos modelos de produção: trabalho e pessoas. Oeiras: Celta, 1998b. p.75-92.

. Sistemas antropocêntricos de produção. In: KOVÁCS, I.; CASTILLO, J. J. Novos modelos de produção: trabalho e pessoas. Oeiras: Celta, 1998c. p. 93- I |4.

. Trabalho, qualificações e aprendizagem ao longo da vida. llusões e problemas da sociedade da informação. In: AAW. Formação, trabalho e tecnologia: para uma nova cultura organizacional. Oeiras: Celta, 1998d. p.69-84.

KOVÁCS, I.; CASTILLO, J. J.. Novos Modelos de produção: trabalho e pessoas. Oeiras: Celta, 1998. p. I-3: Introdução

LETELIER, M. E. Escolaridade e inserção no mercado de trabalho. Cadernos de Pesquisa, n. 107, p. 133-48, 1999.

LEVIN, H.; KELLEY, C. Can Education do it alone? In: . HALSEY, A. H. et al. (orgs.). Education: culture, economy, society. Oxford: Oxford University Press, 1997. p. 240-5I.

LIPIETZ, A. Será impossíve/ um desenvo/vimento ecologicamente viável? Matosinhos: Contemporânea Editora; Câmara Municipal de Matosinhos, 1995.

MELLO, G. N. Cidadania e competitividade: desafios educacionais do terceiro milênio. São Paulo: Cortez, 1993.

MIRANDA, M. G. Novo paradigma de conhecimento e políticas educacionais na Américas Latina. Cadernos de Pesquisa, n. 100, p. 37-48, mar. 1997.

MONIZ, A. B. et al. Sobre o conteúdo formativo do trabalho. In: AAW. Formação, trabalho tecnologia: para uma nova cultura organizacional. Oeiras: Celta, 1998. p. 61-7. 
NUNES, J. S. Perfis sociais juvenis. In: CABRAL, M. V., PAIS, J. M. (coord.). Jovens portugueses de hoje. Oeiras: Celta, 1998. p. I-5।.

OCDE. Employment outlook. Paris: OCDE, 1998.

PAIVA, V.; WARDE, M. J. Novo paradigma de desenvolvimento e centralidade do ensino básico. In: PAIVA, V. (org.) Transformação produtiva e equidade: a questão do ensino básico. Campinas: Papirus, 1994. p.9-40

PETRELLA, R. Reflexões sobre a competitividade. Colóquio/Educação e Sociedade, n. 7, p. 77-90, 1994.

PINTO, J. M. Flexibilidade, segurança e identidades sócio-profissionais. Cadernos de Ciências Sociais, n. 19-20, p. 5-37, 1999.

- Notas sobre o sofrimento na sala de aula e possíveis modos de o atenuar. Território Educativo, n. I, p.4-7, 1997.

. Propostas para o ensino das ciências sociais. Porto: Afrontamento, 1994.

RAINBIRD, H. La Construction sociale de la qualification. In: JOBERT, A.; MARRY, C., TANGUY, L. (orgs.). Éducation et travail en Grande-Bretagne, Allemagne et Italie. Paris: Armand Collin, 1995. p. 231-49.

RHODES, M. A Regulatory conundrum: industrial relations and the social dimension. In: LEIBFRIED, S.; PIERSON, P. (orgs.). European social policy. between fragmentation and integration. Washington D.C.: The Brookings Institution, 1995. p. 78- 122.

. The Social dimension of the single european market: national versus transnational regulation. European Journal of Political Research, n. 19, p. 245-80, 1991.

ROSA, M. T. S. A Qualificação no trabalho ou o entrosar da organização do processo de trabalho com políticas de e na produção, políticas estatais e situação dos assalariados perante o mercado e a reprodução da força de trabalho. Organizações e Trabalho, n. I 5, p. 67-81, 1996.

SANTOS, B. S. Reinventar a democracia. Lisboa: Fundação Mário Soares, Gradiva, 1998.

SHIROMA, E. O.; CAMPOS, R. F. Qualificação e reestruturação produtiva: um balanço das pesquisas em educação. Educação \& Sociedade, v. 18, n. 61, p. 13-35, 1997.

SILVA, L. H. (org.). A Escola cidadã no contexto da globalização. Petrópolis: Vozes, 1998.

SILVA, P. A . A Crítica ao serviço dos surfistas. Revista Crítica de Ciências Sociais, n. 54, p. $91-9,1999$.

STANDING, G. Do trabalho penoso ao decente. Economia Pura: tendências e mercados, n. 21, p. 37-9, 2000. 
. The New insecurities. In: GOWAN, P., ANDERSON, P. (orgs.). The Question of Europe. Londres: Verso, 1997. p. 203-19.

STOER, S. R. Construindo a escola democrática através do "campo de recontextualização pedagógica". Educação, Sociedade \& Culturas, n. I, p. 7-27, 1994.

STOER, S. R.; ARAÚJO, H. C. Escola e aprendizagem para o trabalho num país da (semi)periferia européia. Lisboa: Escher, 1992.

STOER, S.; CORTESÃO, L. Levantando a Pedra: da pedagogia intermulticultural às políticas educativas numa época de transnacionalização. Porto: Afrontamento, 1999.

STOLEROFF, A.; CASACA. Intensidade de trabalho e satisfação na produção magra. In: AAW. Formação, trabalho e tecnologia: para uma nova cultura organizacional. Oeiras: Celta, 1998. p. 165-76.

- Requisitos sociais e culturais da "produção magra" e o processo de indução dos trabalhadores. In: AAW. Novas dinâmicas socioeconómicas: que desafios para a sociologia industrial, das organizações e do trabalho? Lisboa: Câmara Municipal de Lisboa, Associação Portuguesa de Profissionais em Sociologia Industrial, das Organizações e do Trabalho, 1996. p. $179-90$.

STREECK, W. Public power beyond the nation state: the case of the European Community. In: BOYER, R.; DRACHE, D. (orgs.). States against markets: the limits of globalization. Londres: Routledge, 1996. p. 299-3I5.

TADDEI, E. H. "Empregabilidade" e formação profissional: a "nova" face da política social na Europa. In: SILVA, L. H. (org.). A Escola cidadã no contexto da globalização. Petrópolis: Vozes, 1998. p. 340-68.

TANGUY, L. Do sistema educativo ao emprego; formação: um bem universal? Educação \& Sociedade, v. 20, n. 67, p. 48-69, 1999.

. (coord). L'Introuvable relation formation/emplori: un état des recherches en France. Paris: La Documentation Française, 1986.

TEDESCO, J. C. O Novo pacto educativo: educação, competitividade e cidadania na sociedade moderna. Vila Nova de Gaia: FML, 1999.

TOURAINE, A. Carta aos socialistas. Lisboa: Terramar, 1996.

. Como sair do liberalismo? Lisboa: Terramar, 1999.

VILLELA, A.; ALLEN, D. J.; CAFÉ, S. Educação para a competitividade (ou a reconciliação da educação para o trabalho com a educação para a cidadania). Rio de Janeiro: BNDES, 1994.

YOUNG, M. F. D. Uma Abordagem do estudo dos programas enquanto fenómenos do conhecimento socialmente organizado. In: GRÁCIO, S.; STOER, S. R.; MIRANDA, S. (orgs.). 
Sociologia da educação Il: a construção social das práticas educativas. Lisboa: Livros Horizonte, 1982. p. 150-87.

Currículo e democracia: lições de uma crítica à "nova sociologia da educação". Educação e Realidade, v. I4, n. I, p. 29-40, 1989.

. The Curriculum of the future: from the "new sociology of education" to a critical theory of learning. Londres: Falmer, 1998.

YOUNG, M. et al. Unifying academic and vocational learning and the idea of a learning society. Journal of Education Policy, v. 12, n. 6, p. 527-37, 1997. 